\title{
Early Experience with Lung Transplantation in Patients with Idiopathic Pulmonary Fibrosis
}

Iskander Al-Githmi*

Department of Surgery, Division of Cardiothoracic Surgery, King Abdulaziz University Hospital, Jeddah, Saudi Arabia

\author{
Abstract \\ Background: Lung transplant is a treatment option for idiopathic pulmonary fibrosis. The purpose of this study \\ was to review the results of lung transplant in patients with idiopathic pulmonary fibrosis.
}

Methods: Between November 2008 and October 2010, there were 11 patients who had lung transplant at our institution; 6 patients $(55 \%)$ had single lung transplant for idiopathic pulmonary fibrosis. Clinical data were reviewed retrospectively. Follow-up was 4 years.

Results: The 6 patients who received single lung transplant for idiopathic pulmonary fibrosis had no perioperative mortality; 1 patient died within 30 days of surgery because of multiple organ failure that resulted from sepsis, and 1 patient died at 14 months after surgery because of respiratory failure and bronchiolitis obliterans. The overall survival was $83 \%$ at 1 year, $67 \%$ at 2 years, and $67 \%$ at 4 years after transplant.

Conclusions: Lung transplant is effective in reducing the risk of death and prolonging survival in patients with idiopathic pulmonary fibrosis.

Keywords: Respiratory; Immunosuppression; Surgery, Cardiopulmonary bypass

Abbreviations: FVC: Forced Vital Capacity; FEV1: Forced Expiratory Volume in the First Second of Expiration; $\mathrm{PaO}_{2}$ : Arterial Partial Pressure of Oxygen

\section{Introduction}

Lung transplant has been the preferred treatment for $>40$ years for several end-stage pulmonary diseases. The first human lung transplant was performed in 1963 in a patient with bronchogenic carcinoma who died because of renal failure at 18 days after lung transplant [1]. During the next 2 decades, 40 lung transplants were performed, and the only patient who was discharged to home 8 months after transplant died from sepsis. In 1983, the first successful isolated single lung was performed for a patient with idiopathic pulmonary fibrosis [2].

Idiopathic pulmonary fibrosis is a progressive and fatal disease with median survival from 2.8 to 4.8 years, and there is no current therapy that prolongs survival from this disease [3-5]. Lung transplant may be an option in patients with end-stage idiopathic pulmonary fibrosis [6]. However, there is controversy about single or bilateral lung transplant as the better surgical option for patients with idiopathic pulmonary fibrosis.

The purpose of this study was to review the results of lung transplant in patients with idiopathic pulmonary fibrosis.

\section{Materials and Methods}

Between November 2008 and October 2010, there were 11 lung transplant performed at our institution. Recipients were selected according to guidelines of the International Society for Heart and Lung Transplant (Table 1). Diagnosis of idiopathic pulmonary fibrosis was made on high resolution computed tomography of chest and histological patterns of usual interstitial pneumonia. Organs were allocated to recipients based on blood group, size match, and patient status. Single lung transplant was performed for patients with idiopathic pulmonary fibrosis ( 6 patients), scleroderma (1 patient), and lymphangioleiomyomatosis (1 patient); bilateral lung transplant was performed for patients with bronchiectasis (2 patients) and pulmonary hypertension (1 patient). A retrospective review of clinical data for the 6 patients who had single lung transplant for end-stage idiopathic pulmonary fibrosis was done at 4-year follow-up after transplant (Table 2).

\section{Lung preservation}

Donor lungs were preserved with ice-cold low-potassium dextran (50 mL/kg) (Perfadex, Vitrolife, Göteborg, Sweden) mixed with tris (hydroxymethyl) aminomethane buffer, prostaglandin $\mathrm{E}_{1}(500 \mu \mathrm{g})$, and calcium gluconate $(10 \%)$. A bolus of prostaglandin $\mathrm{E}_{1}(500 \mu \mathrm{g})$ was administered directly into the pulmonary artery immediately before antegrade pulmonary artery flush. In addition, an in situ retrograde flush was performed with dextran (1.5 L) (Perfadex, Vitrolife, Göteborg, Sweden).

\section{Lung transplant technique}

In patients with idiopathic pulmonary fibrosis, single lung transplant was performed through an anterolateral thoracotomy. Cardiopulmonary bypass was used in 4 patients (67\%) because of secondary pulmonary hypertension or primary pulmonary hypertension. The lung with the least amount of preoperative ventilation and perfusion was removed initially. The donor lung was prepared at the back table, taking care to preserve peribronchial collateral circulation to the donor lung. The donor bronchus was shortened to 1 cartilage proximal to the upper lobe of the bronchus. Bronchial anastomosis was done with continuous 4-0 polypropylene suture for the membranous part and interrupted 4-0 polypropylene suture for the cartilaginous part. The pulmonary artery and venous anastomoses

*Corresponding author: Iskander Al-Githmi, M.D., FRCSC, FACS, FCCP Department of Surgery, Division of Cardiothoracic Surgery, King Abdulaziz University Hospital, P.O. Box 80215, Jeddah, Saudi Arabia, Tel: 966-2-640-8346; Fax: 966-2640-8347; E-mail: algithmi@hotmail.com

Received January 09, 2013; Accepted May 30, 2013; Published June 07, 2013

Citation: Al-Githmi I (2013) Early Experience with Lung Transplantation in Patients with Idiopathic Pulmonary Fibrosis. Surgery Curr Res 3: 128. doi:10.4172/21611076.1000128

Copyright: @ 2013 Al-Githmi I. This is an open-access article distributed under the terms of the Creative Commons Attribution License, which permits unrestricted use, distribution, and reproduction in any medium, provided the original author and source are credited. 
Citation: Al-Githmi I (2013) Early Experience with Lung Transplantation in Patients with Idiopathic Pulmonary Fibrosis. Surgery Curr Res 3: 128. doi:10.4172/2161-1076.1000128

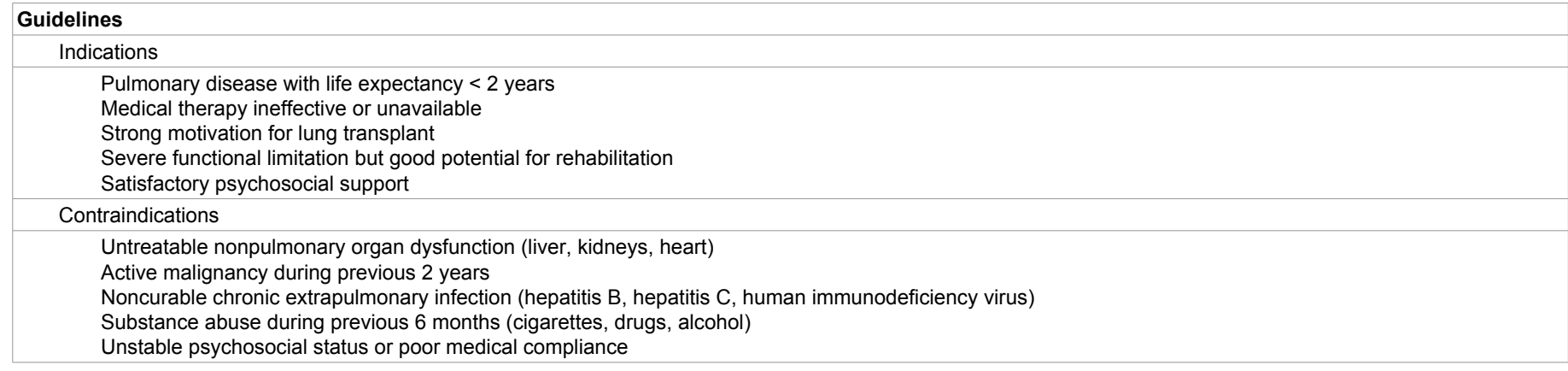

Table 1: Guidelines of indications and contraindications for selection of recipients for lung transplant.

\begin{tabular}{|c|c|}
\hline Parameter & No. or mean (range) \\
\hline Number of patients & 6 \\
\hline Age $(y)$ & 43 (25 to 63 ) \\
\hline \multicolumn{2}{|l|}{ Sex } \\
\hline Men & 2 \\
\hline Women & 4 \\
\hline Body mass index $\left(\mathrm{kg} / \mathrm{m}^{2}\right)$ & 24 (17 to 38$)$ \\
\hline $\mathrm{FEV}_{1}(\%$ predicted $)$ & 29 (20 to 41$)$ \\
\hline FVC (\% predicted) & $28(21$ to 40$)$ \\
\hline 6-minute walk (m) & 115 (70 to 210$)$ \\
\hline $\mathrm{PaO}_{2}$ room air $(\mathrm{mm} \mathrm{Hg})$ & 45 (40 to 53 ) \\
\hline Pulmonary artery pressure $(\mathrm{mm} \mathrm{Hg})$ & $42(27$ to 60$)$ \\
\hline \multicolumn{2}{|l|}{ Type of transplant } \\
\hline Single lung & 6 \\
\hline Bilateral lung & 0 \\
\hline Post op FEV & 58 (41 to 81$)$ \\
\hline $\begin{array}{l}\text { Post op FVC } \\
\text { Cardiopulmonary bypass }\end{array}$ & 60 (42 to 74$)$ \\
\hline Yes & 4 \\
\hline No & 2 \\
\hline
\end{tabular}

*Data reported as number or mean (range, minimum to maximum)

FVC: Forced vital capacity; $\mathrm{FEV}_{1}$ : Forced expiratory volume in the first second of expiration; $\mathrm{PaO}_{2}$ : Arterial partial pressure of oxygen

Table 2: Demographic and Preoperative Clinical Profile of Patients Who Had Lung Transplant for Idiopathic Pulmonary Fibrosis*.

were performed with 5-0 polypropylene suture. The patient was given intravenous low-dose heparin (100 U) and dextran 40 (Rheomacrodex $10 \%$, Medisan Pharmaceuticals) for 7 days after surgery to improve bronchial microcirculation.

\section{Infection prophylaxis}

Infection prophylaxis included broad-spectrum antibiotic and antiviral therapy. Antiviral therapy included ganciclovir (intravenous for 2 weeks and oral for 12 weeks) when the donor or recipient had positive serology for cytomegalovirus. Acyclovir was given for prophylaxis against herpes simplex when the donor or recipient had negative serology for cytomegalovirus. Prophylaxis against Pneumocystis carinii pneumonia included trimethoprim and sulfamethoxazole (double strength, 3 times per week).

\section{Immunosuppression}

All patients received immunosuppression with tacrolimus; mycophenolate mofetil or azathioprine; and prednisone after surgery. Cyclosporine ( $5 \mathrm{mg} / \mathrm{kg}$ given as 1 dose orally) was given immediately before transplant. Tacrolimus dosage was adjusted in response to blood levels (goal during the first 3 months: blood level, 14 to $18 \mathrm{ng}$ / $\mathrm{mL}$; trough level, 8 to $10 \mathrm{ng} / \mathrm{mL}$ ). Intravenous methylprednisolone was administered at surgery $(500 \mathrm{mg}$, given before reperfusion of the allograft), and after surgery ( $0.5 \mathrm{mg} / \mathrm{kg}$ daily for 3 days). Patients were treated with azathioprine $(2 \mathrm{mg} / \mathrm{kg} / \mathrm{d}$, oral) or mycophenolate mofetil ( $1 \mathrm{~g}$, oral, twice daily) for life.

\section{Results}

The 6 patients who received single lung transplant for idiopathic pulmonary fibrosis had no perioperative mortality; 1 patient died within 30 days of surgery because of multiple organ failure that resulted from sepsis, and 1 patient died at 14 months after surgery because of respiratory failure and bronchiolitis obliterans. The overall survival was $83 \%$ at 1 year, $67 \%$ at 2 years, and $67 \%$ at 4 years after transplant. There was no relation between recipient age, body mass index, and use of cardiopulmonary bypass on the duration of mechanical ventilation, length of stay in the intensive care unit, and survival. There were 3 patients $(50 \%)$ who developed acute rejection within the first year. Follow-up at 1 year after surgery showed marked improvement in pulmonary function (Table 2).

\section{Discussion}

Indications for lung transplant have increased and have been extended from patients with noninfectious to infectious parenchymal lung diseases [7]. The United Network for Organ Sharing implemented the Lung Allocation Score in 2005, and this has decreased the waiting 
list time and mortality by giving priority for transplants to more critically ill patients $[8,9]$. In 2000 , idiopathic pulmonary fibrosis was the indication for lung transplant in $15 \%$ patients, and this increased to $37 \%$ lung transplants in 2009 [10]. At our institution, 55\% lung transplants have been performed for idiopathic pulmonary fibrosis. This is a higher proportion than the worldwide experience reported by the International Society for Heart and Lung Transplant registry [11].

Idiopathic pulmonary fibrosis has been reported in men more than women, with a male:female ratio from 1:1 to 2:1. Most (approximately two-thirds) patients worldwide with idiopathic pulmonary fibrosis are aged $>60$ years at presentation (mean age at diagnosis, 66 y) [12]. The present patients were younger and there were more women than men (Table 2).

The outcome of lung transplant may be worse for idiopathic pulmonary fibrosis than other diseases. The relative survival between single and bilateral lung transplant is controversial, with 1 report showing better survival with single lung transplant [13] and another study showing similar mortality for both single and bilateral lung transplant [14]. The largest study that has evaluated lung transplant for idiopathic pulmonary fibrosis included 830 patients from the International Society for Heart and Lung Transplant registry to evaluate the effect of preoperative pulmonary artery pressure; in that study, bilateral lung transplant had a greater risk of early mortality, and elevated pulmonary artery pressure increased the risk of mortality after single lung transplant [15].

Another study that reviewed data from the United Network for Organ Sharing showed that patients who had idiopathic pulmonary fibrosis and who had undergone lung transplant from 1987 through 2009 had an early survival benefit from single lung transplant and a longterm survival benefit from bilateral lung transplant [16]. In addition, primary graft dysfunction was more frequent after bilateral than single lung transplant. Survival after bilateral lung transplant for idiopathic pulmonary fibrosis may be similar to survival after bilateral lung transplant for nonidiopathic pulmonary fibrosis [14]. Patients who have bilateral lung transplant may have a lower frequency of bronchiolitis obliterans syndrome and better results on a 6-minute walk test.

In the present study, the 4-year survival after lung transplant for idiopathic pulmonary fibrosis was $67 \%$, which is lower than survival after lung transplant for nonidiopathic pulmonary fibrosis (80\%). As a result of the severe limitation in number of available donor organs, we perform single lung transplant in patients with pulmonary fibrosis to enable more patients to receive a lung transplant and to shorten the waiting list time. Bilateral lung transplant may achieve better functional recovery and lower frequency of bronchiolitis obliterans than single lung transplant [17]. However, bilateral lung transplant is performed at our institution only for patients with end-stage bronchiectasis and pulmonary hypertension.

Limitations of the present study include the retrospective design and small number of patients. Nevertheless, the present results are satisfactory and provide justification for further study. The frequent use of cardiopulmonary bypass in these patients may reflect the acceptance of transplant as an option for patients with severe illness. In addition, patients with idiopathic pulmonary fibrosis undergoing lung transplant may require cardiopulmonary bypass because idiopathic pulmonary fibrosis may be associated with secondary pulmonary hypertension.

\section{References}

1. Hardy JD (1999) The first lung transplant in man (1963) and the first heart transplant in man (1964). Transplant Proc 31: 25-29.

2. (1986) Unilateral lung transplantation for pulmonary fibrosis. Toronto Lung Transplant Group. N Engl J Med 314: 1140-1145.

3. Bjoraker JA, Ryu JH, Edwin MK, Myers JL, Tazelaar HD, et al. (1998) Prognostic significance of histopathologic subsets in idiopathic pulmonary fibrosis. Am J Respir Crit Care Med 157: 199-203.

4. Mogulkoc N, Brutsche MH, Bishop PW, Greaves SM, Horrocks AW, et al (2001) Pulmonary function in idiopathic pulmonary fibrosis and referral for lung transplantation. Am J Respir Crit Care Med 164: 103-108.

5. Mason RJ, Schwarz MI, Hunninghake GW, Musson RA (1999) NHLB Workshop Summary. Pharmacological therapy for idiopathic pulmonary fibrosis. Past, present, and future. Am J Respir Crit Care Med 160: 1771-1777.

6. Nonn RA, Garrity ER Jr (1998) Lung transplantation for fibrotic lung diseases Am J Med Sci 315: 146-154.

7. Aigner C, Klepetko W (2002) Lung transplantation: state of the art. J Cardiovasc Surg 6: 22-28.

8. Egan TM, Murray S, Bustami RT, Shearon TH, McCullough KP, et al. (2006) Development of the new lung allocation system in the United States. Am J Transplant 6: 1212-1227

9. Arnaoutakis GJ, Allen JG, Merlo CA, Sullivan BE, Baumgartner WA, et al (2011) Impact of the lung allocation score on resource utilization after lung transplantation in the United States. J Heart Lung Transplant 30: 14-21.

10. Christie JD, Edwards LB, Aurora P, Dobbels F, Kirk R, et al. (2009) The Registry of the International Society for Heart and Lung Transplantation: Twenty-sixth Official Adult Lung and Heart-Lung Transplantation Report-2009. J Heart Lung Transplant 28: 1031-1049.

11. Hosenpud JD, Bennett LE, Keck BM, Boucek MM, Novick RJ (2001) The Registry of the International Society for Heart and Lung Transplantation: eighteenth Official Report-2001. J Heart Lung Transplant 20: 805-815.

12. Araki T, Katsura H, Sawabe M, Kida K (2003) A clinical study of idiopathic pulmonary fibrosis based on autopsy studies in elderly patients. Intern Med 42: 483-489.

13. Meyer DM, Edwards LB, Torres F, Jessen ME, Novick RJ (2005) Impact of recipient age and procedure type on survival after lung transplantation for pulmonary fibrosis. Ann Thorac Surg 79: 950-957.

14. Mason DP, Brizzio ME, Alster JM, McNeill AM, Murthy SC, et al. (2007) Lung transplantation for idiopathic pulmonary fibrosis. Ann Thorac Surg 84: 1121 1128

15. Whelan TP, Dunitz JM, Kelly RF, Edwards LB, Herrington CS, et al. (2005) Effect of preoperative pulmonary artery pressure on early survival after lung transplantation for idiopathic pulmonary fibrosis. J Heart Lung Transplant 24 1269-1274.

16. Thabut G, Christie JD, Ravaud P, Castier Y, Dauriat G, et al. (2009) Survival after bilateral versus single-lung transplantation for idiopathic pulmonary fibrosis. Ann Intern Med 151: 767-774.

17. Bando K, Armitage JM, Paradis IL, Keenan RJ, Hardesty RL, et al. (1994) Indications for and results of single, bilateral, and heart-lung transplantation for pulmonary hypertension. J Thorac Cardiovasc Surg 108: 1056-1065. 